\title{
Ceftriaxone-associated nephrolithiasis and gallstone in adults
}

This article was published in the following Dove Press journal: Drug, Healthcare and Patient Safety

\author{
Ghodsiyeh Azarkar' \\ Motahare Mahi Birjand ${ }^{2}$ \\ Alireza Ehsanbakhsh ${ }^{3}$ \\ Bita Bijari' \\ Mohammad Reza Abedini ${ }^{4}$ \\ Masood Ziaee' \\ 'Infectious Disease Research Center, \\ Birjand University of Medical Sciences, \\ Birjand, Iran; ${ }^{2}$ Student Research \\ Committee, Department of Clinical \\ Pharmacy, Faculty of Pharmacy, Shiraz \\ University of Medical Sciences, Shiraz, \\ Iran; ${ }^{3}$ Department of Radiology, Valiasr \\ Hospital, Birjand University of Medical \\ Sciences, Birjand, Iran; ${ }^{4}$ Cellular \\ and Molecular Research Center, \\ Department of Pharmacology, School \\ of Medicine, Birjand University of \\ Medical Sciences, Birjand, Iran
}

Background: Ceftriaxone (CTX) is widely used for the treatment of bacterial infections; however, side effects such as gallstone and nephrolithiasis have been reported in children. There is limited information about urinary tract calculi as CTX side effects in adults. Therefore, the present study was aimed to evaluate the incidence of gallstone and nephrolithiasis following CTX administration.

Methods: The present study was conducted in the Vali-e-Asr Hospital. Eighty-four patients with various infectious diseases with different daily treatment (mean \pm SD: 4.19 \pm 2.54 ) were included in this study, consisting of 49 females and 35 males. The mean of total doses used in patients was 10.2143 (SD: 5.8585). To detect possible gallstone, gallbladder sludge, and urolithiasis, patients were evaluated by serial ultrasound before and after CTX treatment. Patients with renal and hepatobiliary dysfunction were excluded from the study and did not receive any nephrotoxic drugs during this study. Demographic parameters including age, sex, body mass index, dosage of CTX, as well as the duration of treatment and hospitalization were determined. Statistical significances were determined using Fisher's exact test and independent $t$-test.

Results: Results from our study showed that the incidence of gallstone and nephrolithiasis were $8.8 \%$ and $1.5 \%$ following CTX administration, respectively. Surprisingly, we found a significant correlation in terms of age between patients with and without gallstone $(P=0.03)$.

Conclusion: Our findings suggest that the patients' age might play a role in the development of such a complication. This indicates the need for a close monitoring of CTX-treated patients to assess the possible formation of gallstone and nephrolithiasis.

Keywords: ceftriaxone, gallstones, nephrolithiasis, sonography

\section{Introduction}

Ceftriaxone (CTX) is a semisynthetic third-generation cephalosporin, which is widely used for the treatment of various bacterial infections. The drug shows potent antimicrobial activity against a wide variety of bacteria, including Streptococcus faecalis, Streptococcus pyogenes, Streptococcus pneumoniae, Brucella melitensis, Haemophilus influenzae, and Neisseria gonorrhoeae. ${ }^{1-5}$ Because of its long plasma half-life, single daily dosing, beta-lactamase resistance, and potent antibacterial activities against Gramnegative and Gram-positive bacteria, CTX is the antibiotic of choice in most cases. ${ }^{6,7}$ CTX, showing a remarkable stability against beta-hydrolysis, exerts its antimicrobial activity through inhibition of transpeptidase enzymes that are responsible for bacterial cell wall synthesis. ${ }^{8,9}$ Although CTX was shown to be relatively safe, there are complications associated antibiotic treatment, such as gallstone and nephrolithiasis. ${ }^{5}$
Correspondence: Masood Ziaee Birjand Infectious Diseases Research Center, Birjand University of Medical Sciences, Shahid Ayatollah Ghaffari Street, Post Box: 397, Birjand 9717853577, Southern Khorasan Province, Iran Tel +9805632381252

Email proff.masood.ziaee@gmail.com 
It is important to understand such complications due the fact that they can be treated easily. In contrast, confusion regarding these complications may lead to more invasive treatment such as surgery. ${ }^{10}$

Approximately $33 \%-67 \%$ of the administered dose is eliminated through renal excretion, while $40 \%$ is secreted in the bile followed by elimination via the gastrointestinal tract. ${ }^{6,11-13}$ A variety of studies showed that CTX can be concentrated in the bile 20-150 times more than in serum. ${ }^{7,14-17}$ In this condition, CTX can bind to calcium cations in the bile and induce reversible precipitations, resulting in crystallization. ${ }^{18}$ CTX-induced crystals lead to nephrolithiasis, ${ }^{19-22}$ gallstone, and bladder sludge. ${ }^{23-25}$

A variety of studies revealed contradictory results about the incidence of gallstone and nephrolithiasis, as well as predisposing factors such as age, sex, body mass index (BMI), drug dosage, and the duration of treatment. ${ }^{19,21,26}$ Most of the studies also focused on CTX-associated nephrolithiasis and gallstone in children. Nevertheless, there is limited information on urinary tract calculi as one of the side effects of CTX in adults. In this light, the present study was performed to assess the incidence of nephrolithiasis and gallstone associated with CTX administration as well as predisposing factors in adult patients.

\section{Methods}

This quasi-experimental before-and-after study was conducted on 84 patients aged from 15 to 87 (mean age $=55.49 \pm$ 18.94) years and hospitalized with different types of infectious diseases in Birjand University of Medical SciencesAffiliated Hospital (Vali-e-Aser Hospital) from 2011 until 2015. The procedures used in this study were approved by the Ethics Committee of Birjand University of Medical Sciences, Birjand, Iran (ir.bums.REC.1394.419). This study was conducted in accordance with the Declaration of Helsinki. Signed written informed consents were obtained from the patients who participated in the study. In addition, patients' parent provided written informed consent for any participant below 18 years of age. Pneumonia (78.9\%) and gastroenteritis $(8.8 \%)$ were found to be the most common causes of hospital admission, respectively. All patients were examined for liver and kidney health before the study. Patients suffering from renal and hepatobiliary dysfunction were excluded from the study. This is also important to note that patients did not take any nephrotoxic drugs. Patients received different daily treatment of CTX (mean \pm SD: $4.19 \pm 2.54$ ) and the mean of used total dose was 10.2143 (SD: 5.8585 ). To assess the health of the biliary and urinary tracts, all the patients were examined with sonography by a radiologist immediately before the treatment. Only cases with normal sonographic features were included in the study. In specific cases, the results were confirmed by two radiologists. The patients were also evaluated by the same radiologist for kidney and gallbladder stones by serial ultrasound during and after CTX treatment to detect possible gallstone, gallbladder sludge, and urolithiasis. The serum levels of urea, creatinine, bilirubin, and hepatic enzymes were recorded before and after treatment of all patients. All patients received CTX alone without additional antibiotics.

The presence of mobile and gravity-dependent materials, accompanied by a clear acoustic shadow, was considered as the criterion for a positive sonographic examination. In addition, low-level echo materials lined in the dependent portion of the gallbladder without acoustic shadowing were diagnosed as biliary sludge. Positive sonographic findings were reassessed and confirmed by another sonographist. When sonographic features of complications and renal symptoms and/or biliary symptoms were detected in the patients, CTX treatment discontinued and the supportive care and treatment were carried out for 10 days followed by sonography in the first 2 weeks and every 2 weeks until these findings were completely normalized. The data were statistically analyzed using SPSS version 19 (SPSS Inc., Chicago, IL, USA). Statistical significances were determined using Fisher's exact test and independent $t$-test. $P$-values of 0.05 or less were considered to be statistically significant.

\section{Results}

The present study was performed on 84 patients, including 49 (58.3\%) females and $35(41.7 \%)$ males. Out of 84 patients, 78 $(92.9 \%)$ were married and most patients were living in rural areas. Demographic parameters, including patients' age, sex, BMI, CTX dosage as well as the duration of treatment and hospitalization, were assessed as shown in Table 1.

Posttreatment sonographic evaluation showed nephrolithiasis in $1(1.5 \%)$ and gallstone in $6(8.8 \%)$ of the 84 patients. Table 2 represents the characteristics of patients with nephrolithiasis and gallstone. It is also worth to mention that size (mean $\pm \mathrm{SD}$ ) of kidney stone and gallstone in these patients was $4.41 \pm 1.69$ and $11.74 \pm 13.35 \mathrm{~mm}$, respectively.

Comparison of the groups with or without gallstone demonstrated no significant differences with respect to BMI, drug dosage, and the duration of treatment (Tables 3 and 4). Importantly, there was a significant difference between gallstone and age $(P=0.03$; Table 4$)$. 
Table I Demographic characteristics of patients

\begin{tabular}{|c|c|c|c|c|}
\hline \multicolumn{2}{|l|}{ Parameter } & \multirow{2}{*}{$\begin{array}{l}\mathbf{N} \\
35\end{array}$} & \multirow{2}{*}{$\begin{array}{l}\% \\
41.7\end{array}$} & \multirow{2}{*}{$\begin{array}{l}\text { Mean } \pm \text { SD } \\
-\end{array}$} \\
\hline Sex & Male & & & \\
\hline & Female & 49 & 58.3 & \\
\hline \multirow[t]{5}{*}{ Age (years) } & $<40$ & 20 & 23.8 & \multirow[t]{5}{*}{$55.49 \pm 18.94$} \\
\hline & $40-50$ & 11 & 13.1 & \\
\hline & $50-60$ & 17 & 20.3 & \\
\hline & $60-70$ & 15 & 17.8 & \\
\hline & $>70$ & 21 & 25 & \\
\hline \multirow[t]{3}{*}{ BMI } & Normal & 56 & 66.7 & \multirow[t]{3}{*}{$23.57 \pm 5.75$} \\
\hline & Overweight (25-30) & 19 & 22.2 & \\
\hline & Obese $(\geq 30)$ & 19 & II.I & \\
\hline Length of treatment (days) & \multicolumn{3}{|l|}{-} & $4.19 \pm 2.54$ \\
\hline Number of drug dosage & \multicolumn{3}{|l|}{-} & $2.06 \pm 0.38$ \\
\hline Starting doses $(\mathrm{g})$ & \multicolumn{3}{|l|}{-} & $1.09 \pm 0.29$ \\
\hline Total dose & \multicolumn{3}{|l|}{-} & $10.21 \pm 5.85$ \\
\hline
\end{tabular}

Abbreviation: BMI, body mass index.

Table 2 Characteristics of patients with nephrolithiasis and gallstone

\begin{tabular}{|l|l|l|l|l|l|}
\hline Patient no. & Sex & Age (years) & Reason for hospitalization & Lithiasis (calculi) & Drug dose (g) \\
\hline I & M & 39 & Pneumonia & Nephrolithiasis & I \\
2 & F & Not available & UTI & Gallstone & I \\
3 & F & 87 & UTI & Gallstone & 2 \\
4 & F & 43 & Pneumonia & Gallstone & I \\
5 & M & 85 & Gastroenteritis & Gallstone & I \\
6 & F & 68 & Pneumonia & Gallstone & I \\
7 & F & 82 & Pneumonia & Gallstone & I \\
\hline
\end{tabular}

Abbreviation: UTI, urinary tract infection.

Table 3 Comparison of drug doses, the number, and duration of drug use in patients with or without gallstone

\begin{tabular}{|l|l|l|l|}
\hline Variables & With $(\mathbf{n = 6})$ & Without (n=78) & P-value \\
\cline { 2 - 3 } & Mean \pm SD & Mean \pm SD & \\
\hline Starting dose (g) & $1.16 \pm 0.40$ & $1.06 \pm 0.24$ & 0.37 \\
Dose of treatment duration (g/dose) & $1.00 \pm 0.00$ & $1.16 \pm 0.53$ & 0.5 \\
Number of drug use (within 24 hours) & $2.00 \pm 0.00$ & $2.06 \pm 0.38$ & 0.31 \\
Treatment duration (days) & $5.33 \pm 4.04$ & $4.10 \pm 2.18$ & 0.42 \\
\hline
\end{tabular}

Table 4 Comparison of BMI and age in patients with or without gallstone

\begin{tabular}{|l|l|l|l|}
\hline Variables & With $(\mathbf{n}=6)$ & Without $(\mathbf{n}=\mathbf{7 8})$ & P-value \\
\cline { 2 - 3 } & Mean \pm SD & Mean \pm SD & \\
\hline Age & $73.00 \pm 18.34$ & $54.15 \pm 18.99$ & 0.03 \\
Weight & $53.40 \pm 11.78$ & $59.74 \pm 13.62$ & 0.31 \\
BMI & $22.49 \pm 2.57$ & $23.27 \pm 5.23$ & 0.74 \\
\hline
\end{tabular}

Abbreviation: BMl, body mass index.

In addition, our results showed that there are no significant differences between the two groups and those with comorbid gastroenteritis and pneumonia ( $P=0.43$; Table 5). No significant differences were also found between gallstone as with patient's sex $(P=0.46)$.
Table 5 Comparison of comorbid conditions in patients with or without gallstone

\begin{tabular}{|l|l|l|l|}
\hline Disease & $\begin{array}{l}\text { With } \\
\text { gallstone } \\
(\mathbf{n = 6 )}\end{array}$ & $\begin{array}{l}\text { Without } \\
\text { gallstone } \\
(\mathbf{n = 7 8 )}\end{array}$ & \multirow{2}{*}{-value } \\
\cline { 2 - 3 } & $\mathbf{n}(\%)$ & $\mathbf{n}(\%)$ & \\
\hline Gastroenteritis & $\mathrm{I}(16.6)$ & $4(5.1)$ & 0.19 \\
\hline Pneumonia & $2(33.3)$ & $30(38.4)$ & 0.43 \\
\hline Other & $0.0(0.0)$ & $5(6.4)$ & - \\
\hline
\end{tabular}

\section{Discussion}

In the present study, our results have demonstrated that the incidence of gallstone and nephrolithiasis following CTX therapy was $8.8 \%$ and $1.5 \%$, respectively. Interestingly, we 
also found a significant difference in terms of age between patients with and without gallstone $(P=0.03)$. It is important to note that patients were showed acute urinary tract infection and exhibited no risk factors for stone development. In addition, the absence of stones was confirmed using sonography before the patients received CTX.

CTX, as an anion, can lead to reversible pseudolithiasis, which forms an insoluble salt with calcium and, like bilirubin, can precipitate with calcium. ${ }^{27} \mathrm{~A}$ variety of studies revealed a significant incidence of CTX-associated urolithiasis, demonstrating that gallstone and nephrolithiasis are complications of CTX therapy. ${ }^{18,28,29}$ However, the incidence of gallstone in CTX-treated patients varies among studies.

In an early study in 1988 , Schaad et $\mathrm{al}^{10}$ reported a reversible CTX-induced gallstone in $40 \%$ (16 of 37 ) of severely ill children following high doses of CTX. In 1990, Cochat et al described a 13 -year-old boy with meningitis who revealed the gallstone following 9 days of CTX therapy. ${ }^{30}$ In addition, de Moor et al reported a 7-year-old boy with CTX-associated nephrolithiasis and gallstone 4 days after treatment initiation. ${ }^{27}$ Stone formation was attributed to a high CTX dose $(100 \mathrm{mg} / \mathrm{kg} /$ day in severe infections vs $125 \mathrm{mg} / \mathrm{kg} /$ day in their patient).

In another study carried out by Palanduz et al, ${ }^{31} \mathrm{CTX}$ was administered at a dosage of $100 \mathrm{mg} / \mathrm{kg} /$ day for $1-3$ weeks to 118 children, 8 and 12 of whom were found to have gallbladder sludge and pseudolithiasis, respectively. In addition, the incidence rate of gallstone was reported to be $17 \%$. The abnormalities were resolved after stopping the CTX. In parallel, Prince and Senac reported a 14-year-old boy showing both CTX-induced gallstone and nephrolithiasis, who was being treated with CTX (4 g/day) for epidural abscess. ${ }^{32}$ The patient was recovered after stopping the CTX therapy. In 2004, Avci et $\mathrm{al}^{19}$ found that children receiving a high CTX dose (100 $\mathrm{mg} / \mathrm{kg} /$ day) for the treatment of severe infections developed positive sonographic findings, representing the small renal stones and nephrolithiasis in $4(7.8 \%)$ of 51 children. In a study carried out by Acun et al, ${ }^{33}$ gallbladder and urinary tract precipitations developed in 5 of 35 children treated with CTX, 1 with gallbladder sludge, 1 with gallstone and urinary bladder sludge, and 3 with gallstone. Interestingly, their findings indicated predominance in females, inconsistent with other above-mentioned studies. Moreover, Ozturk et $\mathrm{al}^{34}$ reported the $57.6 \%$ incidence of pseudolithiasis and sludge in the gallbladder of patients receiving CTX. In 2006, Biner et $\mathrm{al}^{35}$ reported abnormal gallbladder sonograms and urolithiasis in $17 \%$ and $0.6 \%$ of children receiving CTX, respectively. Importantly, patients with pseudolithiasis were older and treated with higher drug doses. Similar to other studies, they reported that gallstone usually occurs in children receiving high doses of CTX. Furthermore, Araz et $\mathrm{al}^{36}$ in 2007 demonstrated that children receiving CTX $100 \mathrm{mg} / \mathrm{kg} /$ day for meningitis developed biliary sludge and gallstones.

At the same time, in a study performed by Mohkam et al, ${ }^{21}$ the incidence rate of nephrolithiasis was found to be $1.4 \%$ for 284 children with pyelonephritis who were treated with 75 $\mathrm{mg} / \mathrm{kg}$ intravenous CTX. They suggested that CTX-treated patients may be at an increased risk of kidney stone formation. In 2011, Chutipongtanate and Thongboonkerd ${ }^{20}$ showed that CTX is crystallized with free calcium in dose- and time-dependent manner. Calcium-depletion assay revealed that crystallization required free calcium as a substrate. In another study performed by Fesharakinia et al in 96 children who received 50-100 mg/kg/day CTX, nephrolithiasis and gallbladder stones were developed in $6(6.3 \%)$ and $1(1 \%)$ patients, respectively. ${ }^{37}$ Additionally, Tsukagoshi et al showed that patients with central nervous system infections, who were treated with CTX (4 g/day) for 35-69 days, developed CTX-induced pseudolithiasis and nephrolithiasis. ${ }^{38}$

In contrast to the results obtained by the above-mentioned studies, a significant difference in terms of age was found in this study. Therefore, the present study suggests that young adults may be at an increased risk for the formation of urinary stones during CTX therapy. Consistent with our study, Ettestad et al suggested that biliary sludge and pseudolithiasis may be more prevalent in younger patients. However, it is believed that the disease is dose-dependent and, more commonly, occurs in children receiving higher doses.${ }^{39}$ Consistent with studies carried out by Mohkam et $\mathrm{al}^{21}$ and Avci et al, ${ }^{19}$ no significant difference was found in terms of sex between patients with and without gallstones. However, Fesharakinia et $\mathrm{al}^{37}$ showed that there was a significant correlation between nephrolithiasis and male sex. As Acun et al mentioned, ${ }^{33}$ variations in the methodology, including the infection nature, fasting, hydration, antibiotic dose, duration and infusion rate of CTX treatment, as well as the timing of the first ultrasonographic control, can explain the differences in the prevalence of the CTX-associated abnormalities.

A few limitations of this study have to be considered. First, the sample size of this study is rather limited; however, it has to be taken into consideration that the results obtained revealed significant association with patients' age. In addition, the present study assessed the data from a single hospital; the findings of the research may not be more reliable than multicenter studies. 


\section{Conclusion}

In summary, the results of this study have demonstrated that the incidence of gallstone and nephrolithiasis following CTX therapy was $8.8 \%$ and $1.5 \%$, respectively. Our findings also have suggested that the patients' age might play a role in the development of CTX-associated gallstone $(P=0.03)$. However, comparison of the groups with or without gallstone demonstrated no significant differences with respect to patient's sex, BMI, drug dosage of CTX, and the duration of treatment with CTX. Considerably, more studies are required to closely monitor CTX-treated patients regarding possible gallbladder and kidney stone formation.

\section{Acknowledgments}

The authors would like to express their appreciation to all contributors who have made the achievement of this study. This work was supported by a research grant (453) from vice chancellor for research, Birjand University of Medical Sciences.

\section{Disclosure}

The authors report no conflicts of interest in this work.

\section{References}

1. Mischnik A, Baumert P, Hamprecht A, et al; DZIF-ATHOS Study Group. In vitro susceptibility to 19 agents other than $\beta$-lactams among third-generation cephalosporin-resistant Enterobacteriaceae recovered on hospital admission. JAntimicrob Chemother. 2017;72(5):1359-1363.

2. Pacifici GM, Marchini G. Clinical pharmacology of ceftriaxone in neonates and infants: effects and pharmacokinetics. Int J Pediatr. 2017;5(9):5751-5778.

3. Kaye KS, Pogue JM. Infections caused by resistant Gram-negative bacteria: epidemiology and management. Pharmacotherapy. 2015;35(10):949-962.

4. Pfaller MA, Flamm RK, Duncan LR, Mendes RE, Jones RN, Sader HS Antimicrobial activity of tigecycline and cefoperazone/sulbactam tested against 18,386 Gram-negative organisms from Europe and the Asia-Pacific region (2013-2014). Diagn Microbiol Infect Dis. 2017;88(2):177-183.

5. Wang S, Huang X, Xu Q, Xu T. Research progress of mechanisms of ceftriaxone associated nephrolithiasis. Mini Rev Med Chem. 2017;17(17): 1584-1587.

6. Arvidsson A, Alván G, Angelin B, Borgå O, Nord CE. Ceftriaxone: renal and biliary excretion and effect on the colon microflora. J Antimicrob Chemother. 1982;10(3):207-215.

7. Richards D, Heel R, Brogden R, Speight T, Avery G. Ceftriaxone. A review of its antibacterial activity, pharmacological properties and therapeutic use. Drugs. 1984;27(6):469-527.

8. Neu HC. Relation of structural properties of beta-lactam antibiotics to antibacterial activity. Am J Med. 1985;79(2A):2-13.

9. Raju KS, Reddy KNK, Vasu K. Prescribing pattern for infectious diseases in tertiary care pediatric hospital. Indian J Res Pharm Biotechnol. 2017;5(1):68.

10. Schaad UB, Wedgwood-Krucko J, Tschaeppeler H. Reversible ceftriaxone-associated biliary pseudolithiasis in children. Lancet. 1988;2(8625):1411-1413.

11. Park HZ, Lee SP, Schy AL. Ceftriaxone-associated gallbladder sludge. Identification of calcium-ceftriaxone salt as a major component of gallbladder precipitate. Gastroenterology. 1991;100(6):1665-1670.
12. Xia Y, Lambert KJ, Schteingart CD, Gu JJ, Hofmann AF. Concentrative biliary secretion of ceftriaxone. Inhibition of lipid secretion and precipitation of calcium ceftriaxone in bile. Gastroenterology. 1990;99(2):454-465.

13. Brogard JM, Blickle JF, Jehl F, Arnaud JP, Paris-Bockel D, Monteil H. High biliary elimination of ceftriaxone in man. Int J Clin Pharmacol Ther Toxicol. 1988;26(4):167-172.

14. Neu HC, Meropol NJ, Fu KP. Antibacterial activity of ceftriaxone (Ro 13-9904), a beta-lactamase-stable cephalosporin. Antimicrob Agents Chemother. 1981;19(3):414-423.

15. McNamara PJ, Stoeckel K, Ziegler WH. Pharmacokinetics of ceftriaxone following intravenous administration of a $3 \mathrm{~g}$ dose. Eur J Clin Pharmacol. 1982;22(1):71-75.

16. Heim-Duthoy KL, Caperton EM, Pollock R, Matzke GR, Enthoven $\mathrm{D}$, Peterson PK. Apparent biliary pseudolithiasis during ceftriaxone therapy. Antimicrob Agents Chemother. 1990;34(6):1146-1149.

17. Zinberg J, Chernaik R, Coman E, Rosenblatt R, Brandt LJ. Reversible symptomatic biliary obstruction associated with ceftriaxone pseudolithiasis. Am J Gastroenterol. 1991;86(9):1251-1254.

18. Dursun M, Otunctemur A, Ozbek E. Kidney stones and ceftriaxone. Eur Med J. 2015;3(1):68-74.

19. Avci Z, Koktener A, Uras N, et al. Nephrolithiasis associated with ceftriaxone therapy: a prospective study in 51 children. Arch Dis Child. 2004;89(11):1069-1072.

20. Chutipongtanate S, Thongboonkerd V. Ceftriaxone crystallization and its potential role in kidney stone formation. Biochem Biophys Res Commun. 2011;406(3):396-402.

21. Mohkam M, Karimi A, Gharib A, et al. Ceftriaxone associated nephrolithiasis: a prospective study in 284 children. Pediatr Nephrol. 2007;22(5):690-694.

22. Gargollo PC, Barnewolt CE, Diamond DA. Pediatric ceftriaxone nephrolithiasis. J Urol. 2005;173(2):577-578.

23. Acun C, Erdem LO, Sogut A, Erdem CZ, Tomac N, Gundogdu S. Ceftriaxone-induced biliary pseudolithiasis and urinary bladder sludge. Pediatr Int. 2004;46(3):368-370.

24. Ustyol L, Bulut MD, Agengin K, et al. Comparative evaluation of ceftriaxone- and cefotaxime-induced biliary pseudolithiasis or nephrolithiasis: a prospective study in 154 children. Hum Exp Toxicol. 2017;36(6):547-553.

25. Krzemień G, Książczyk T, Szmigielska A, et al. Ceftriaxone-associated acute gallbladder enlargement - an unexpected diagnosis in the child with urinary tract infection. Dev Period Med. 2015;19(2):182-185.

26. Dooki MR, Norouzi A. Cholelithiasis in childhood: a cohort study in north of Iran. Iran J Pediatr. 2013;23(5):588.

27. de Moor RA, Egberts AC, Schröder CH. Ceftriaxone-associated nephrolithiasis and biliary pseudolithiasis. Eur J Pediatr. 1999;158(12):975-977.

28. Li N, Zhou X, Yuan J, Chen G, Jiang H, Zhang W. Ceftriaxone and acute renal failure in children. Pediatrics. 2014;133(4):e917-e922.

29. Besim H, Arslan K. Ceftriaxone associated acute cholecystitis. Arch Balkan Med Union. 2016;51(2):258-260.

30. Cochat P, Cochat N, Jouvenet M, et al. Ceftriaxone-associated nephrolithiasis. Nephrol Dial Transplant. 1990;5(11):974-976.

31. Palanduz A, Yalçin I, Tonguç E, et al. Sonographic assessment of ceftriaxone-associated biliary pseudolithiasis in children. J Clin Ultrasound. 2000;28(4):166-168.

32. Prince JS, Senac MO. Ceftriaxone-associated nephrolithiasis and biliary pseudolithiasis in a child. Pediatr Radiol. 2003;33(9):648-651.

33. Acun C, Erdem LO, Sögüt A, et al. Gallbladder and urinary tract precipitations associated with ceftriaxone therapy in children: a prospective study. Ann Trop Paediatr. 2004;24(1):25-31.

34. Ozturk A, Kaya M, Zeyrek D, Ozturk E, Kat N, Ziylan SZ. Ultrasonographic findings in ceftriaxone: associated biliary sludge and pseudolithiasis in children. Acta Radiol. 2005;46(1):112-116.

35. Biner B, Öner N, Çeltik C, et al. Ceftriaxone-associated biliary pseudolithiasis in children. J Clin Ultrasound. 2006;34(5):217-222. 
36. Araz N, Okan V, Demirci M, Araz M. Pseudolithiasis due to ceftriaxone treatment for meningitis in children: report of 8 cases. Tohoku J Exp Med. 2007;211(3):285-290.

37. Fesharakinia A, Ehsanbakhsh AR, Ghorashadizadeh N. Ceftriaxoneassociated nephrolithiasis in children. Iran J Pediatr. 2013;23(6): 643.
38. Tsukagoshi S, Ishizawa K, Hirayanagi K, et al. Progressive pseudolithiasis associated with the intravenous administration of ceftriaxone in patients with central nervous system infections. Intern Med. 2017;56(23):3189-3192.

39. Ettestad PJ, Campbell GL, Welbel SF, et al. Biliary complications in the treatment of unsubstantiated Lyme disease. J Infect Dis. 1995;171(2):356-361.

\section{Publish your work in this journal}

Drug, Healthcare and Patient Safety is an international, peer-reviewed open access journal exploring patient safety issues in the healthcare continuum from diagnostic and screening interventions through to treatment, drug therapy and surgery. The journal is characterized by the rapid reporting of reviews, original research, clinical, epidemiological and post-marketing surveillance studies, risk management, health literacy and educational programs across all areas of healthcare delivery. The manuscript management system is completely online and includes a very quick and fair peer-review system. Visit http://www.dovepress.com/ testimonials.php to read real quotes from published authors.

Submit your manuscript here: https://www.dovepress.com/drug-healthcare-and-patient-safety-journal 